\title{
AS CONTRIBUIÇÕES DA EDUCAÇÃO AMBIENTAL NA POLÍTICA NACIONAL DE RESÍDUOS SÓLIDOS
}

\begin{abstract}
Eliane Maria da Silva Santiago ${ }^{1}$
RESUMO. O presente trabalho tem como objetivo analisar a Política Nacional de Resíduos Sólidos e o Plano Nacional de Resíduos Sólidos, indicando a importância da Educação Ambiental como instrumento de divulgação e contribuição à efetivação de políticas públicas voltadas à redução de impactos oriundos da geração de resíduos. Essa relação será realizada no sentido de encontar as formas e as possibilidades de integração de tais instrumentos no ensino. A Educação Ambiental aparece como um dos instrumentos imprescindíveis para o cumprimento da legislação ambiental, uma vez que a mesma não deve ser vinculada somente à passagem de conhecimentos sobre a natureza, mas à possibilidade de ampliação da participação política dos cidadãos. A noção relativa à Política Pedagógica dos 3 R's será enfatizadas ao longo desse trabalho, no sentido de propor ações de redução e reutilização dos bens de consumo, e de combate ao desperdício. A relevância da educação ambiental em favor de uma sociedade mais justa e sustentável é cada vez mais reconhecida por se constituir um dos meios de enfrentamento da degradação socioambiental, em escala local, nacional e global. Em vista disso, a educação ambiental vem demandando fortemente a gestão por meio de políticas, programas e ações orientadas para a formação de uma cidadania associada à sustentabilidade em todas as suas necessidades.
\end{abstract}

Palavras-chaves: políticas públicas; sustentabilidade; meio ambiente

\section{THE CONTRIBUTIONS OF ENVIRONMENTAL EDUCATION IN THE NATIONAL SOLID WASTE POLICY}

\begin{abstract}
The objective of this study is to analyze the National Solid Waste Policy and the National Solid Waste Plan, indicating the importance of Environmental Education as an instrument for dissemination and contribution to the implementation of public policies aimed at reducing impacts from waste generation. This relationship will be realized in order to find the forms and possibilities of integration of such instruments in education. Environmental Education appears as one of the essential instruments for compliance with environmental legislation, since it should not be linked only to the passage of knowledge about nature, but to the possibility of broadening the political participation of citizens. The notion of the Pedagogical Policy of the 3 R's will be emphasized throughout this work, in the sense of proposing actions to reduce and reuse consumer goods, and to combat waste. The relevance of environmental education in favor of a more just and sustainable society is increasingly recognized as one of the means of coping with socio-environmental degradation at local, national and global levels. In view of this, environmental education has strongly demanded management

\footnotetext{
${ }^{1}$ Graduada em engenharia civil - ênfase em estruturas pela Universidade Veiga de Almeida; graduada em Licenciatura plena em Construção Civil pela faculdade Bethencourt da Silva; pôs graduada em Engenharia Estrutural pelo Centro Universitário Augusto Motta; Mestranda em Desenvolvimento Local pelo Centro Universitário Augusto Motta- UNISUAM.
} 
through policies, programs and actions oriented towards the formation of a citizenship associated with sustainability in all its needs.

Keywords: public policies; sustainability; environment

\section{Introdução}

As leis que regulamentam os resíduos sólidos são um modelo que pretende reduzir os impactos causados pelo consumismo exarcerbado, cujo o êxito depende de ações de Educação Ambiental que tem como centro a Política Pedagógica dos 3 R’s, que significa Reduzir, Reutilizar e Reciclar, que priorize as iniciativas de redução e reutilização sobre as de reciclagem.

De acordo com Layrargues (1998), a questão do lixo vem sendo apontada pelos ambientalistas como um dos mais sérios problemas ambientais urbanos da contemporaneidade, a ponto de ter se tornado objeto de proposições teóricas para seu enfrentamento e alvo privilegiado de programas de educação ambiental nas escolas brasileiras. A compreensão da necessidade do gerenciamento integrado dos resíduos sólidos permitiu a formulação da chamada Política ou Pedagogia dos 3R's (Reduzir, Reutilizar e Reciclar), que impõe técnica e pedagogias para o enfrentamento da questão do lixo. Apesar de ser um assunto complexo, muitos programas de educação ambiental na escola são implementados de maneira simples, uma vez que, em função da reciclagem, desenvolvem apenas a Coleta Seletiva de Lixo, em detrimento de uma análise crítica e abrangente acerca dos valores culturais da sociedade de consumo, modo de produção capitalista.

Campbell (2001, p.58) afirma que

A sociedade de consumo caracteriza-se, antes de tudo, pelo desejo socialmente expandido da aquisição "do supérfluo", do excedente, do luxo. Do mesmo modo, se estrutura pela marca da insaciabilidade, da constante insatisfação, onde uma necessidade preliminarmente satisfeita gera quase automaticamente outra necessidade, num ciclo que não se esgota, num continuum onde o final do ato consumista é o próprio desejo de consumo.

Em relação a essa tendência pragmática, pouco esforço tem sido dedicado à análise do significado ideológico da reciclagem e suas implicações para a educação 
ambiental reducionista, mais preocupada com a promoção de uma mudança comportamental sobre a técnica da disposição domiciliar do lixo do que com a reflexão sobre a mudança dos valores culturais que sustentam o estilo de produção e consumo da sociedade moderna.

A aprovação da Lei $n^{o}$ 12.305/10, que regulamenta a Política Nacional de Resíduos Sólidos (PNRS), após longos anos de discussões no Congresso Nacional sinalizou o início de uma forte articulação institucional envolvendo União, Estados e Municípios, o setor produtivo e a sociedade civil na busca de soluções para os sérios problemas causados pelos resíduos, que vem prejudicando a qualidade de vida dos da população brasileira.

Para que as diretrizes da PNRS sejam cumpridas são indispensáveis a criação de instrumentos e metodologias de mobilização capazes de influenciar os diferentes segmentos da sociedade, inclusive os profissionais do setor e a população como um todo. Este papel de mobilização compete à Educação Ambiental.

No decorrer do texto será feita uma distinção entre o discurso ecológico oficial e o discurso ecológico alternativo. Com isso, buscamos apontar que as políticas públicas desenvolvidas até então priorizam apenas a reciclagem como solução ao problema dos resíduos sólidos, se utilizando da Educação Ambiental para reforçar a ideologia consumista dirigida apenas a reciclagem. $\mathrm{Na}$ sequência, são definidas as noções relativas à Política Pedagógica dos 3 Rs bem como a ordem de prioridade de cada "R". Ao final do artigo, a pedagogia dos 3 Rs será revisada sob a perspectiva do discurso ecológico formal e do discurso ecológico alternativo, apresentando os principais desafios da Educação Ambiental frente aos dois modelos majoritários de argumentação e postura ideológica que envolvem a geração e o gerenciamento dos resíduos sólidos.

O presente trabalho tem como objetivo analisar a Política Nacional de Resíduos Sólidos e o Plano Nacional de Resíduos Sólidos, indicando a importância da Educação Ambiental como instrumento de divulgação e contribuição à efetivação de políticas públicas voltadas à redução de impactos oriundos da geração de resíduos.

\section{A política nacional de resíduos sólidos}

A Política Nacional de Resíduos Sólidos - PNRS, criada pela Lei nº 12.305, de 2010 e regulamentada pelo Decreto $\mathrm{n}^{\circ}$ 7.404, de 2010, estabelece princípios, objetivos, 
diretrizes, metas e ações, e importantes instrumentos, tais como o Plano Nacional de Resíduos Sólidos, que contemplará os diversos tipos de resíduos gerados, alternativas de gestão e gerenciamento passíveis de implementação, bem como metas para diferentes cenários, programas, projetos e ações correspondentes (BRASIL, 2010).

O Plano mantém estreita relação com os Planos Nacionais de Mudanças do Clima (PNMC), de Recursos Hídricos (PNRH), de Saneamento Básico (Plansab) e de Produção e Consumo Sustentável (PPCS). Apresenta conceitos e propostas que refletem a interface entre diversos setores da economia compatibilizando crescimento econômico e preservação ambiental com desenvolvimento sustentável (BRASIL, 2012).

O sucesso da implantação de um Plano Nacional de Resíduos Sólidos, instrumento fundamental de política pública nesta área temática, exige novos conhecimentos, olhares e posturas de toda a sociedade. Para que soluções adequadas se desenvolvam, conciliando os objetivos de desenvolvimento socioeconômico, preservação da qualidade ambiental e promoção da inclusão social, torna-se necessário um processo de organização e democratização das informações, de modo a fazerem sentido e mobilizarem o interesse, a participação e o apoio dos vários públicos (BRASIL, 2011).

Para tanto, o Plano Nacional de Resíduos Sólidos, conta com a Política Nacional de Educação Ambiental - PNEA, que em seu artigo $1^{\circ}$ define "a educação ambiental como processos por meio dos quais o indivíduo e a coletividade constroem valores sociais, conhecimentos, habilidades, atitudes e competências voltadas para a conservação do meio ambiente, bem de uso comum do povo, essencial à sadia qualidade de vida e sua sustentabilidade" (BRASIL, 1999). Em seu artigo $2^{\circ}$, estabelece que a educação ambiental é um componente essencial da educação nacional, devendo estar presente em todos os níveis de ensino de forma articulada, contínua e permanente, de modo formal e não formal (BRASIL, 1999), sendo esta uma condição essencial para o atendimento da demanda educativa que apresenta a Política e o Plano Nacional de Resíduos Sólidos, tanto na orientação e ampla difusão de seus conceitos, quanto na capacitação de cada um dos segmentos da cadeia geradora e destinadora dos resíduos (BRASIL, 2010).

Nesse contexto, em atendimento à Política Nacional de Resíduos Sólidos, estabelecida pela Lei ${ }^{\circ} 12.305$ de 2010, o Plano Nacional de Resíduos Sólidos lança diretrizes, estratégias e metas que, de forma geral, integram e demandam ações de 
educação ambiental e de comunicação social, que sejam capazes de mobilizar e envolver toda a sociedade brasileira, incluindo as esferas governamentais, as instituições não governamentais e os segmentos produtivos (BRASIL, 2010).

De acordo com o Plano Nacional de Resíduos Sólidos (2012), o termo educação ambiental, quando ligado aos resíduos sólidos, deve abarcar formas distintas de comunicação e de relacionamento com a população, quais sejam:

a) informação, sensibilização ou mobilização para o tema resíduos sólidos, desenvolvido em ambiente escolar: o conteúdo desenvolvido tem claro objetivo pedagógico e normalmente o tema Resíduos Sólidos é trabalhado para chamar a atenção e sensibilizar a comunidade escolar para as questões ambientais de uma forma mais ampla. Podem envolver desde informações objetivas até mais aprofundadas, além de tratamento pedagógico e didático específico para cada caso, faixa etária e nível escolar.

b) informações orientadoras e objetivas para a participação da população ou de determinada comunidade em programas ou ações ligadas ao tema resíduos sólidos (ensino informal): normalmente está ligada a objetivos ou metas específicas dentro do projeto ou ação em que aparece, por exemplo, informações objetivas a respeito de como aquela população deve proceder na segregação dos seus resíduos para uma coleta seletiva municipal ou qual o procedimento mais adequado para o encaminhamento de determinados resíduos, entre outras informações pertinentes.

c) sensibilização e/ou mobilização das comunidades diretamente envolvidas (ensino informal): os conteúdos a serem trabalhados devem envolver um aprofundamento das causas e consequências do excesso de geração e na dificuldade de cuidado, tratamento e destinação adequados dos resíduos sólidos produzidos em um município, região ou país. Neste caso ainda os conteúdos variam e podem incluir desde os vários aspectos ligados ao cuidado com os recursos naturais e à minimização de resíduos (3Rs), até os vários temas relacionados à educação para o consumo sustentável/consciente/responsável e às vantagens sociais e econômicas da coleta seletiva.

d) Campanhas e Ações Pontuais de Mobilização (ensino informal): os conteúdos, instrumentos e metodologias devem ser adequados a cada caso específico: a complexidade do tema e a necessidade premente de mudança de hábitos e 
atitudes necessários à implantação dos novos princípios e diretrizes presentes na PNRS impossibilitam que estas ações alcancem todos os objetivos e metas propostos em um trabalho educativo. Podem, entretanto, fazer parte de programas mais abrangentes de educação ambiental, podendo ainda envolver um público mais amplo, a partir da utilização das várias mídias disponíveis, inclusive aquelas com grande alcance e impacto junto à população.

Segundo o Plano Nacional de Resíduos Sólidos, um tipo de comunicação muito desenvolvido em ambiente escolar, comunidades ou na grande mídia, ainda que chamado comumente de educação ambiental, apresenta, em seus conteúdos e métodos, características que se assemelham às ações de marketing ou até mesmo às ações de fortalecimento de uma determinada marca, produto ou material, muitas vezes se preocupando unicamente com a concorrência empresarial e não com a conscientização ambiental (BRASIL, 2011).

Layrargues (1998) ilustrar o tipo de situação mencionada acima com um exemplo: lata de alumínio. Segundo este autor a preferência por esta embalagem de bebidas demonstra o significado do discurso ecológico oficial sobre a mudança de padrão de consumo: O alumínio, descartável, foi eleito como exemplo da mudança ecologicamente correta, devido à sua reciclabilidade, antes da embalagem de vidro retornável. A reciclabilidade tornou-se um ato de maior significado ecológico do que a retornabilidade (reutilização). O resultado foi o aumento do consumo de bebidas gaseificadas embaladas em latas de alumínio promovido por uma campanha de marketing bem-sucedida em favor da embalagem de alumínio e em detrimento de seus concorrentes. A indústria de embalagens de alumínio, em um exemplo de cooptação ideológica, reuniu oportunidades para recuperar matéria-prima a baixo custo e promover uma maior penetração de seu produto, por meio de uma educação ambiental que recompensa comportamentos tidos como ambientalmente corretos sob a pesrpectiva da ideologia hegemônica (LAYRARGUES, 1998).

Atividades desta natureza, segundo o Plano Nacional de Resíduos Sólidos, devem ser diferenciadas da educação ambiental, uma vez que fogem das diretrizes da PNEA. Por outro lado, ações éticas e responsáveis de empresas ou instituições, muitas vezes ligadas a sistemas de gestão sustentáveis, como a ISO 14000 ou 26000, devem ser apoiadas (BRASIL, 2011). 
No entanto, ainda são consideráveis as dificuldades dos gestores, técnicos, educadores, integrantes dos vários setores da sociedade, assim como da população em geral, com relação ao novo modelo de participação social envolvendo o tema Resíduos Sólidos. É pequeno o número de municípios que investem em posturas diferenciadas e que consideram o problema de forma inovadora. (BRASIL, 2011).

Situação semelhante é percebida com relação à prática de ações duradouras e efetivas de comunicação ou educação focadas na redução da geração de resíduos, assim como na diminuição do desperdício. A maioria das experiências tem investido grande parte de seus recursos humanos e financeiros em ações de Educação Ambiental restritas ao ambiente escolar, desconsiderando a população e/ou as comunidades diretamente envolvidas com os projetos ou programas pertinentes ao tema (BRASIL, 2011).

A partir da elaboração dos planos estaduais e municipais de resíduos surgirá a necessidade de diferenciar educação ambiental formal da educação ambiental não formal. Sempre que um programa ou projeto for implantado em determinada comunidade ou região, aquela população deve ser claramente focalizada e assim informada, sensibilizada e mobilizada para a participação. Por outro lado, observa-se ainda a necessidade de políticas públicas claras e efetivas na criação de um cenário de comunicação ou pedagógico mais uniforme para o país, na medida em que muitos dos problemas envolvendo resíduos estão ligados ao nosso padrão de produção e consumo (BRASIL, 2012).

\section{O que dizem os discursos dos ambientalistas}

Carvalho (1991), ao analisar o discurso ambientalista governamental, aponta a existência de duas matrizes discursivas sobre a questão ambiental: um discurso ecológico oficial, enunciado pelo governo, representante da ideologia hegemônica ${ }^{2}$ e encarregado de manter os valores culturais instituídos na sociedade; e um discurso ecológico alternativo, emitido pelo ambientalismo original, gerado pelos movimentos

\footnotetext{
${ }^{2} \mathrm{O}$ conceito de hegemonia desenvolvido por Antonio Gramsci ajuda-nos a desvendar os jogos de consenso e dissenso que atravessam e condicionam a produção simbólica nos meios de comunicação, interferindo na conformação do imaginário social e nas disputas de sentido e de poder na contemporaneidade. No entender de Gramsci, a hegemonia pressupõe a conquista do consenso e da liderança cultural e político-ideológica de uma classe ou bloco de classes sobre as outras. Além de congregar as bases econômicas, a hegemonia tem a ver com entrechoques de percepções, juízos de valor e princípios entre sujeitos da ação política (GRAMSCI, 2001).
} 
sociais organizados, representantee da ideologia contra-hegemônica ${ }^{3}$ e encarregado de disseminar valores que contestam a ordem social e econômica instituída.

Layrargues (1998) afirma que apesar da possibilidade de articulação estratégica para o enfrentamento de determinados problemas ambientais, o ideário do ambientalismo alternativo opõe-se ao oficial. Enquanto o oficial deseja manter o status quo, o alternativo deseja transformá-lo. Desse modo, cada composição ideológica terá uma determinada visão da questão do lixo, uma determinada leitura do significado da Política dos 3R's e, no que se refere à educação ambiental, um conjunto de proposições pedagógicas diferentes, de acordo com a visão de mundo e os interesses que as inspiram.

Para Layrargues (1998), a questão do lixo é um problema de ordem cultural para o discurso ecológico alternativo, que situa a cultura do consumismo como um dos alvos da crítica à sociedade moderna. O consumismo é o item mais expressivo da crítica da sociedade sustentável (MARTELL, 1994). Desde que Adam Smith afirmou que a produção tem como finalidade o consumo, a economia se estabeleceu com o objetivo aumentá-lo, e ele passou a ser entendido culturalmente como sinônimo de bem-estar. Contudo, o problema é que atualmente o consumismo é visto também como responsável por uma série de problemas ambientais, e desse modo, não pode mais ser compreendido unicamente como sinônimo de felicidade (EKINS, 1998).

Penna (1999) afirma que a sociedade moderna está tomada de valores consumistas e tudo leva a crer que a tarefa da redução do consumo será árdua, pois será necessário reverter valores culturais enraizados, favorecidos pela intensa invasão da vida pública e doméstica.

Atualmente, a prática educativa corrente se insere na lógica da metodologia da resolução de problemas ambientais locais de modo pragmático, tornando a reciclagem do lixo uma atividade-fim, ao invés de considerá-la um tema-gerador para o questionamento das causas e consequências da questão do lixo (LAYRARGUES, 1998).

\footnotetext{
${ }^{3}$ A contra-hegemonia institui o contraditório e a tensão no que até então parecia uníssono e estável. Um dos desafios centrais para o pensamento contra-hegemônico consiste em alargar a visibilidade pública de enfoques ideológicos que contribuam para a reorganização de repertórios, princípios, e variáveis de identificação e coesão, com vistas à alteração gradual e permanente das relações sociais e de poder. Para isso, são fundamentais campanhas, mobilizações e pressões sociais por legislações que detenham a forte concentração do setor nas mãos de um reduzido número de corporações (GRAMSCI, 2001).
} 
Blauth (1996) afirma que .a avaliação da problemática dos resíduos sólidos tem sido enfocada apenas na reciclagem, a qual tem a capacidade de produzir uma forma de tranquiliar a consciência dos indivíduos, que podem passar a consumir mais produtos, sobretudo descartáveis, sem constrangimento algum, pois agora são recicláveis e, portanto, ecológicos. As indústrias que utilizam símbolos reacionados à reciclabilidade nos rótulos de seus produtos criam a suposição da reciclabilidade garantida e infinita, além da suposição de que a embalagem é inerentemente ecológica, quando na verdade o próprio símbolo torna-se um componente estimulador da descartabilidade, reforçando a ideologia do consumismo.

Kligerman (2000) aponta que é importante informar isso a sociedade, pois, teoricamente, ela orienta a demanda. Mas também se faz necessário avançar esse raciocínio e questionar o educador e o que se ensina; do contrário, a prática educativa poderá ser alvo da dominação ideológica.

Ao se referir ao meio ambiente, Layrargues (1998) argumenta que a educação é identificada como a solução para todos os nosso problemas. O autor acredita que é por intermédio da escola, um instrumento de dominação, que se mantém a ideologia hegemônica e os interesses da classe dominante. A educação é um aparelho ideológico ${ }^{4}$ que se torna palco permanente de conflito entre interesses conservadores e libertários.

Para Almeida (1992) a educação ambiental progressista é concebida como instrumento de transformação social, não visa apenas à internalização da pauta ambiental na escola e na sociedade, pois seu verdadeiro sentido é a promoção da reflexão dos valores fundamentais da sociedade moderna e das instituições que se valem desses princípios para dominar, oprimir e explorar tanto a natureza como certas camadas da sociedade.

\footnotetext{
${ }^{4}$ Althusser (1985, p.68) designa pelo nome de aparelhos ideológicos do Estado, um certo número de realidades que apresentam-se ao observador imediato sob a forma de instituições distintas e especializadas. Propomos uma lista empírica, que deverá necessariamente ser examinada em detalhe, posta a prova, retificada e remanejada. Com todas as reservas que esta exigência acarreta podemos, pelo momento, considerar como aparelhos ideológicos do Estado as seguintes instituições (a ordem de enumeração não tem nenhum significado especial): religiosos (o sistema das diferentes Igrejas), escolar (o sistema das diferentes escolas" públicas e privadas), familiar, político (o sistema político, os diferentes Partidos), sindical, de informação (a imprensa, o rádio, a televisão, etc), cultural (Letras, Belas Artes, esportes, etc)
} 


\section{A política pedagógica: reduzir, reutilizar e reciclar}

De acordo com o Plano Nacional de Resíduos Sólidos (2011) a definição clara de conteúdos, metodologias e instrumentos ligados ao tema Educação Ambiental e Resíduos deve dedicar especial atenção aos conceitos ligados à Política Pedagógica dos 3 Rs. O conceito dos 3 Rs é um eixo orientador de uma das práticas mais necessárias ao equacionamento da questão dos Resíduos Sólidos e ao sucesso do PNRS e demais planos, projetos e ações decorrentes, principalmente àqueles ligados à minimização da quantidade de resíduos a serem dispostos e à viabilização de soluções ambientais, econômicas e sociais adequadas (BRASIL, 2000).

a) Reduzir a Geração de Resíduos em consonância com a percepção de que resíduos em excesso significam ineficiência de processo, caso típico da atual sociedade de consumo. Este conceito envolve não só mudanças comportamentais, mas também novos posicionamentos do setor empresarial como o investimento em projetos ecológicos, entre outros (BRASIL, 2011).

b) Reutilizar: aumentando a vida útil dos materiais e produtos e o combate à obsolescência programada, entre outras ações de médio e grande alcance. É importante ampliar a relevância do conceito, muitas vezes confundido e limitado à implantação de pequenas ações de reutilização de materiais que resultam em objetos ou produtos de baixo valor agregado, descartáveis e /ou sem real valor econômico ou ambiental. Estas práticas têm sido comumente disseminadas como solução para o sério problema de excesso de geração e disposição inadequada de resíduos e compõem muitas vezes, em escolas e comunidades, grande parte do que é considerado como educação ambiental (BRASIL, 2011).

c) Reciclar: valorizando a segregação dos materiais e o encaminhamento adequado dos resíduos secos e úmidos, apoiando desta forma, os projetos de coleta seletiva e a diminuição da quantidade de resíduos a serem dispostos em consonância com as diretrizes da Política Nacional de Resíduos Sólidos (BRASIL, 2011). 


\section{A pedagogia dos 3 Rs sob a perspectiva do discurso ecológico oficial e do discurso ecológico alternativo}

De acordo com Layrargues (1998), no que diz respeito à Pedagogia dos 3R's, o discurso ecológico alternativo sustenta uma sequência lógica a ser seguida: a redução do consumo deve ser priorizada sobre a reutilização e reciclagem; e depois da redução do consumo, a reutilização deve ser priorizada sobre a reciclagem. Langenbach (1998) acrescenta ainda que a reutilização deve ser considerada concomitantemente à redução do consumo, pois ambos criticam o consumismo.

Por outro lado, Layrargues (1998) alerta sobre o discurso ecológico oficial que entende que a questão do lixo é, antes de tudo, um problema de ordem técnica, e não cultural. Se para o discurso ecológico alternativo a questão é o próprio consumismo, o discurso ecológico oficial, que divulga seus ideais sobre a questão do consumo através da Agenda 21 (BRASIL, 2000), entende que é o consumo insustentável. É fundamental perceber que a compreensão do problema é diferente para os dois modelos discursivos: enquanto a posição ideológica do discurso alternativo é radical e subversiva, a posição do discurso oficial é moderada e conservadora, na medida em que qualifica o consumo como insustentável, pressupondo, assim, a possibilidade da existência de um consumo sustentável. O consumo sustentável é propiciado pela aliança da reciclagem com as tecnologias limpas e eficientes. A ideologia hegemônica permite a crítica ao consumo insustentável porque hoje existe um consumo sustentável; no entanto, não se permite a crítica ao consumismo, pois a frugalidade representa uma subversão perigosa demais ao sistema econômico dominante.

Existem, portanto, duas interpretações possíveis sobre o significado da Política dos 3R's. Para o discurso ecológico oficial, não faz sentido propor uma redução do consumo, pois o problema para ele não é o consumismo, mas o consumo insustentável (LAYRARGUES, 1998).

Há então dois modos de ação derivados das possibilidades de compreensão da Política dos 3R's: o primeiro prioriza a redução e reutilização e articula-se com o projeto político-ideológico progressista; o outro prioriza a reciclagem e articula-se com o projeto liberal. Se a Agenda 21, representante do discurso ecológico oficial, não considera o consumismo como o problema, não surpreende que se tenha omitido 
quanto à redução do consumo no documento. E se a cultura do consumismo é o alvo da mudança de valores preconizada pelo discurso ecológico alternativo, a reciclagem revela-se contraditória em relação à redução do consumo e à reutilização, pois ela não ameaça o sistema dominante, já que não questiona o consumismo (LAYRARGUES, 1998). Até mesmo o Clube de Roma reconhece que o aumento da vida útil dos bens, a diminuição da obsolescência planejada, a recuperação dos bens deteriorados e a reutilização de bens descartados são estratégias mais eficientes que a reciclagem, pois demandam menos energia para a conversão (MEADOWS ET AL., 1992).

A eliminação da obsolescência planejada é a chave da minimização dos resíduos. A vida útil dos produtos torna-se cada vez mais curta, e nem poderia ser diferente, pois há uma união entre a obsolescência planejada e a criação de demandas artificiais no capitalismo. A moda e a propaganda provocam um verdadeiro desvio da função primária dos produtos. Ocorre que a obsolescência planejada e a descartabilidade são hoje elementos vitais para o modo de produção capitalista, por isso encontram-se presentes tanto no plano material como simbólico (SEWELL, 1978).

Layrargues (1998) argumenta que o discurso ecológico oficial altera a ordem de prioridade da Pedagogia dos 3R's: conferindo máxima importância à reciclagem, em detrimento da redução do consumo e do reaproveitamento. A Pedagogia dos 3R's preconizada pelo discurso ecológico oficial torna-se uma prática comportamentalista, ao invés de reflexiva, pois reduz a os 3R's à Pedagogia da Reciclagem. Nessa conjuntura, emerge o problema da mudança do padrão de produção e consumo advogada pelo ambientalismo alternativo, que visualiza a necessidade tanto da mudança qualitativa da produção, alterando insumos e matrizes energéticas, como a diminuição da descartabilidade e a eliminação da obsolescência planejada material e simbólica, conforme salienta o Tratado sobre Consumo e Estilo de Vida (LA ROVÈRE; VIEIRA, 1992).

Sosa (1992) exemplifica o tom discursivo do ambientalismo oficial ao afirmar que a reciclagem não só possibilita o aumento da vida útil dos materiais, gerando novos invesimentos empresariais, como também contribui para a proteção ambiental. Reconhece ainda que para que a reciclagem seja uma solução viável e concreta ao 
problema ambiental da indústria, o fator educativo é fundamental para a geração de comportamentos adequados diante do lixo, estimulando-se uma correta disposição dos resíduos sólidos, que facilitam sua seletividade e posterior reciclagem. Layrargues (2002) acrescenta ainda a necessidade de não alterar os atuais valores culturais.

Guimarães (1995) afirma que o mecanismo da estratégia de dominação ideológica é o conservadorismo dinâmico: o discurso ecológico oficial aceita o alternativo antes que se torne ameaçador para a seguir absorver-lhe apenas os elementos compatíveis - a reciclagem, a redução do desperdício e o reaproveitamento - suprimindo-lhe o elemento crítico - a redução do consumo. O efeito dessa estratégia para o ambientalismo alternativo é anestésico, pois os grupos sociais dessa vertente veem o discurso da reciclagem como uma conquista gradual de suas reivindicações, ingenuamente despercebendo a anulação do poder crítico da ideologia contra-hegemônica. Figueiredo (1994) entende a preferência pela reciclagem nos programas de Coleta Seletiva de Lixo como uma prática que se adapta perfeitamente ao modelo economicista atual. Do mesmo modo, Zacarias (1998) atesta que apesar de o discurso oficial representar avanços aparentes no pensamento ecológico, sua efetivação não tem buscado soluções definitivas, pois acarretariam prejuízos aos atores sociais representantes da ideologia hegemônica.

Adams (1995) intitula esse fenômeno como "compensação do risco": ele age quando um risco passa a ser controlado, e a atitude humana volta-se para a aceitação de um outro risco. Se o consumismo gera um risco ambiental para a sociedade moderna por meio do esgotamento dos recursos naturais e da saturação dos depósitos de lixo, criam-se mecanismos que garantem o controle desse risco, o que aqui se traduz pela reciclabilidade. Dessa forma, segundo Layrargues (1998), ao invés de se reduzir o consumo, cria-se a oportunidade de manter o padrão convencional de consumo, pois a ameaça torna-se relativamente controlada, e a reciclagem passa a desempenhar a função de compensação do risco do consumismo. Contudo, trata-se de uma falsa segurança, que significa a alienação da realidade, a qual cumpre a função de gerar a sensação de que um comportamento ambientalmente correto, a reciclagem, contribuirá para a resolução de um problema, quando, na verdade, camufla a crítica ao consumismo. Recicla-se para não se reduzir o consumo. Afinal, a 
reciclagem representa, além da salvação da cultura do consumismo, a permanência da estratégia produtiva da descartabilidade e da obsolescência planejada, permitindo a manutenção do caráter expansionista do capitalismo (LAYRARGUES, 1998).

Zaneti (1997, p. 14) resume a questão ao afirmar que "de nada adiantam campanhas para reciclar e programas de Coleta Seletiva de Lixo se não fizermos um trabalho de internalização de novos hábitos e de atitudes para que, num futuro próximo, não haja mais lixo excessivo e a sua causa, o consumo desmedido, tenha sido controlada".

\section{Conclusão}

Diante do aumento do consumo, a problemática dos resíduos sólidos e o seu devido equacionamento inscrevem-se na dimensão de um novo paradigma civilizatório, de uma nova maneira de ver e pensar a produção e o consumo. É necessária, portanto, uma transformação envolvendo modelos e valores que darão novo significado ao próprio desenvolvimento.

Os objetivos da Política Nacional de Educação Ambiental (PNEA) estão de acordo com esse referencial quando buscam desenvolver uma compreensão integrada do meio ambiente em suas múltiplas e complexas relações, garantindo a democratização das informações relativas ao meio ambiente, estimulando e fortalecendo uma consciência crítica sobre o problema ambiental, e incentivando a participação individual e coletiva, permanente e responsável, na preservação do equilíbrio do meio ambiente, entendendo-se a defesa da qualidade ambiental como um valor inseparável do exercício da cidadania.

Este diagnóstico deixa evidente a importância do investimento em um Plano de Educação ambiental, com novas estratégias e linguagens, capazes de aumentar a mobilização da sociedade. A Política Nacional de Resíduos Sólidos representa um grande progresso na redução e reutilização dos bens de consumo previstos na Pedagogia proposta pelos 3 Rs, estimulando profundas reflexões na sociedade contemporânea, mergulhada no mito da reciclagem como ato de combate ao desperdício e de compensação dos padrões de produção e consumo estabelecidos.

Deste modo, o grande desafio da Educação Ambiental diante da problemática dos resíduos sólidos está em conceber e pôr em prática iniciativas que priorizem a 
redução e a reutilização dos bens de consumo por meio de programas interdisciplinares que possam mobilizar os indivíduos consumidores. com vistas à mudança de comportamento de toda a sociedade.

\section{Referências}

ADAMS, J. Risk: the policy implications of risk compensation and plural rationalities. London: UCL Press, 1995.

ALMEIDA, J.M. de. Educação como instrumento de transformação. In:INEP. Desenvolvimento e Educação Ambiental. Brasília: INEP, 1992.

ALTHUSSER, Louis. Aparelhos ideológicos de estado. 8 ed. Rio de janeiro: Edições Graal, 2001.

BARBOSA, Lívia. Sociedade de consumo. Rio de Janeiro: Jorge Zahar, 2004.

BLAUTH, P. Rotulagem ambiental e consciência ecológica. Debates Socioambientais. São Paulo, n. 2, p.10-12, 1996.

BRASIL. Lei $n^{\circ}$ 9.795, de 27 de abril de 1999. Dispõe sobre a educação ambiental, institui a Política Nacional de Educação Ambiental e dá outras providências. Diário Oficial da República Federativa do Brasil, Brasília, DF, 28 abr. 1999.

BRASIL. Lei $\mathrm{n}^{\mathrm{o}}$ 12.305, de 2 de agosto de 2010. Institui a Política Nacional de Resíduos Sólidos; altera a Lei $\mathrm{n}^{0}$ 9.605, de 12 de fevereiro de 1998; e dá outras providências. Diário Oficial da República Federativa do Brasil, Brasília, DF, 03 ago. 2010.

BRASIL. MINISTÉRIO DO MEIO AMBIENTE. Plano Nacional de Resíduos Sólidos. Versão preliminar para consulta pública. Brasília, DF, 01 set. 2011.

BRASIL. MINISTÉRIO DO MEIO AMBIENTE. Plano Nacional de Resíduos Sólidos. Brasília, DF, 01 ago. 2012.

BRASIL. Agenda 21: Conferência das Nações Unidas sobre Meio Ambiente e Desenvolvimento. Brasília, Senado Federal, 3 ed., 2000.

CAMPBELl, Colin. A Ética Romântica e o Espírito do Consumismo Moderno. Rio de Janeiro, 2001.

CARVALHO, I.C.M. Territorialidades em luta: uma análise dos discursos ecológicos. São Paulo: Instituto Florestal. Série Registros n. 9, 1991.

EKINS, P. Can humanity go beyond consumerism? Development. London, n. 41, p. 23-27, 1998. 
FIGUEIREDO, P.J.M. A sociedade do lixo: os resíduos, a questão energética e a crise ambiental. Piracicaba: UNIMEP, 1994.

GUIMARÃES, R.P. O desafio político do desenvolvimento sustentado. Lua Nova. São Paulo, n. 35, p. 113-136, 1995.

GRAMSCI, Antonio. Temas de cultura. Ação Católica. Americanismo e fordismo. Rio de Janeiro: Civilização Brasileira, 2001.

KLIGERMAN, D.C. A era da reciclagem $\mathrm{x}$ a era do desperdício. In: SISINNO, C.L.S. \& OLIVEIRA, R.M. de. (Org.) Resíduos sólidos, ambiente e saúde: uma visão multidisciplinar. Rio de Janeiro: Fiocruz, 2000. p. 99-110.

LANGENBACH, M. A rede ecológica. Rio de Janeiro: PUC, 1997.

La ROVÈRE, A.L. \& VIEIRA, L. (Org.) Tratados das ONG's aprovados no Fórum Internacional de ONG's e Movimentos Sociais no âmbito do Fórum Global: Tratado sobre Consumo e Estilo de Vida. Rio de Janeiro, Fórum Brasileiro de ONG's e Movimentos Sociais para o Meio Ambiente e Desenvolvimento, 1992.

LAYRARGUES, P.P. O cinismo da reciclagem: o significado ideológico da reciclagem da lata de alumínio e suas implicações para a educação ambiental. In: LOUREIRO, C.F., LAYRARGUES, P.P. \& CASTRO, R.S. (Org.) Educação Ambiental: repensando o espaço da cidadania. São Paulo: Cortez, 1998.

MARTELL, L. Ecology and Society: an introduction. Cambridge: Polity Press, 1994.

MEADOWS, D.H. Beyond the limits: confronting global colapse, envisioning a sustainable future. Vermont: Chelsea Green Publishing Co., 1992.

PENNA, C.G. O Estado do Planeta: sociedade de consumo e degradação ambiental. Rio de Janeiro: Record, 1999.

SEWELL, G.H. Administração e controle da qualidade ambiental. São Paulo: USP, 1978.

SOSA, M.A. Reciclage: solución empresarial al problema de los desechos solidos. Reciclage, alternativa ambientalista. Caracas: Adan, 1992.

ZACARIAS, R. Coleta seletiva de lixo nas escolas e parceria com empresa: relato crítico de uma experiência. 1998. 120 f. Dissertação de Mestrado, PUCRJ, Rio de Janeiro, 1998.

ZANETI, I. Além do lixo. Reciclar: um processo de transformação. Brasília: Terra Una, 1997. 